\title{
LINGUAGEM E DIFERENÇA: espaços e encontros na formação docente em ensino religioso ${ }^{1}$
}

\author{
Langage et différence: espace et rencontres dans \\ la formation du corps enseignant
}

\author{
Lílian Blanck de Oliveira ${ }^{a}$, Simone Riske-Koch ${ }^{\mathrm{b}}$ \\ ${ }^{\text {a }}$ Professora do Programa de Mestrado em Desenvolvimento Regional da Universidade \\ Regional de Blumenau, Santa Catarina - Brasil, e-mail: lilianbo@uol.com.br

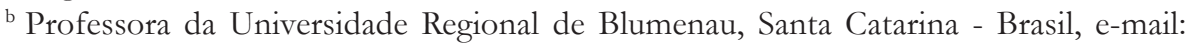 \\ srkoch@terra.com.br
}

\begin{abstract}
Resumo
As percepções e construções em relação ao sagrado integram o substrato cultural dos povos, cujos relatos e registros elaborados sistematicamente pela humanidade se constituem em uma rica fonte de conhecimentos a instigar, desafiar, conflitar e subsidiar as gerações. A linguagem busca expressar, anunciar e pronunciar diferentes olhares, leituras, sentimentos e vivências que pessoas, culturas e povos vão organizando em relação ao que os circundam. O cotidiano escolar é um dos espaços onde continuamente transitam sujeitos e conhecimentos cujas vivências e redes de significados se percebem entretecidas com questões, que circunscrevem e indicam a presença do religioso de forma plural. O Ensino Religioso, em conformidade com a LDBEN n. 9394/96, nova redação do artigo 33 (Lei 9475/97) e Resolução 02/98 do Conselho Nacional de Educação o Ensino
\end{abstract}

Este texto toma por base o primeiro capítulo da pesquisa de mestrado: Discurso e Ensino Religioso: um olhar a partir da diferença (FURB/SC) de Simone Riske-Koch e a palestra: Formação e docência em Ensino Religioso: passos, com-passos e (des)com-passos entre teorias e práticas apresentada no IV Simpósio de Ensino Religioso (EST/RS) por Lílian Blanck de Oliveira.

Rev. Diálogo Educ., Curitiba, v. 8, n. 23, p. 245-262, jan./abr. 2008 
Religioso, é disciplina de matrícula facultativa, compreendida como parte integrante da formação do cidadão e constitui-se em uma das dez áreas do conhecimento do Ensino Fundamental. O respeito à diversidade cultural religiosa do Brasil e a isenção de quaisquer formas de proselitismo são critérios estabelecidos no texto de lei. O presente texto busca fazer algumas aproximações conceituais sobre linguagem e diferença no intento de sinalizar possíveis referências, para estudos e discussões da temática em relação à formação de educadores para a área de conhecimento de Ensino Religioso.

Palavras-chave: Linguagem; Diferença; Formação docente; Ensino religioso.

\section{Resumé}

Les perceptions et les constructions par rapport au sacré incorporent le substrat culturel des peuples, dont les récits et les registres élaborés systématiquement pour l'humanité se constituent une riche source de connaissance à instiguer, défier et subsistir les générations. Le langage cherche à exprimer, annoncer et prononcer différents regards, lectures, sentiments et les vécus que les personnes, cultures et peuples oraganisent par rapport à ce que les entourent. Le quotidien scolaire est un des espaces où continuellement transitent sujets et connaissances dont les expériences et réseaux de définitions (sens) se voient entretisser avec des questions que circonscrivent et indiquent la présence du religieux. L'enseignement religieux en conformité avec la LDBE n. 9394/96 nouvelle redaction de l'article 33 (loi 9475/ 97 et résolution 02/98 du Conseil National d'Éducation de l'enseignement religieux est branche optionnelle, inclue comme partie intégrante de la formation du citoyen et constitue une des dixième branches de la connaissance de l'enseignement fondamental. Le respect à diversité culturelle religieuse du Brésil et l'exemption de n'importe quelles formes de prosélytisme sont des critères établi dans le texte de loi. L'actuel texte cherche faire quelques approches conceptuelles sur le langage et différence dans l'intente de signaler les possibles références, pour des études et discussions de la thématique quant à formation de formateurs pour l'enseignement religieux.

Mots-clés: Langage ; Différence ; Formation du corps enseignant, Enseignement religieux. 
As palavras são tecidas a partir de uma multidão de fios ideológicos e servem de trama a todas as relações sociais em todos os domínios.

É portanto claro que a palavra será sempre o indicador mais sensível de todas as transformações sociais. Mikhail Bakhtin

\section{PALAVRAS INICIAIS}

A sociedade brasileira é marcada por uma diversidade cultural que encanta, intriga e desafia estudos, convivências e pesquisas em todas as áreas. Uma educação comprometida com a diversidade de seus sujeitos e situações requer de toda a sociedade e, particularmente da comunidade escolar, um conjunto de reflexões e práticas, que abordem as diferenças dentro e além dos seus espaços e lugares.

Pensar as diferenças em sua multiplicidade de textos e contextos, presença das singularidades na pluralidade buscando romper uma perspectiva monocultural de educação histórica é pauta intransferível para todo e qualquer processo de formação. As diferenças apreendidas como propriedades inerentes dos seres humanos tendem a estabelecer categorizações e atribuir identidades, fixando uma demarcação social - quem é quem, ou ainda, o que seria bom e aceitável socialmente, ou não. Segundo Woodward (2003, p. 18), "todas as práticas de significação que produzem significados envolvem relações de poder, incluindo o poder para definir quem é incluído e quem é excluído", assim a identidade, marcada pela diferença e geralmente sustentada pela exclusão, adquire "sentido por meio da linguagem e dos sistemas simbólicos pelos quais são representadas".

A linguagem busca expressar, anunciar e pronunciar diferentes sentimentos e posturas que pessoas, culturas e povos vão organizando e expressando em relação ao que os circundam. Ela também pode instalar conflitos e contribuir na construção das diferenças, uma vez que, "a linguagem não apenas expressa relações, poderes, lugares, ela os institui; ela não apenas veicula, mas produz e pretende fincar diferenças" (LOURO, 1997, p. 65).

As diferentes percepções e elaborações relativas ao sagrado integram o substrato cultural dos povos, cujos relatos e registros elaborados sistematicamente pela humanidade se constituem em uma rica fonte de conhecimentos a instigar, desafiar, conflitar e subsidiar as gerações. O cotidiano escolar é um dos espaços onde continuamente transitam sujeitos e conhecimentos cujas vivências e redes de significados se percebem entretecidas com questões que circunscrevem e indicam a presença do religioso a partir de olhares, leituras e práticas diferenciados.

O debate sobre formação docente para o Ensino Religioso tem mobilizado os educadores nas últimas décadas, no tocante aos muitos desafios da sociedade brasileira em relação à diversidade cultural presente no cotidiano escolar.

Rev. Diálogo Educ., Curitiba, v. 8, n. 23, p. 245-262, jan./abr. 2008 
Os educadores responsáveis pela formação docente para o Ensino Religioso, atentos às exigências de um contexto em constante reconfiguração, buscam avaliar o processo em desenvolvimento, pesquisando e discutindo ênfases, ausências e necessidades percebidas em relação aos desafios postos.

Segundo Oliveira e Schlögel (2007), as múltiplas e diferentes linguagens de homens e mulheres, educandos e educadores, que transitam no contexto escolar são vozes, que como janelas se abrem pronunciando, desafiando e requerendo mundos, olhares, leituras e vivências em perspectivas de alteridade e compromisso com a construcão de um mundo melhor e possivel.

Nesse sentido, o presente texto busca fazer algumas aproximações conceituais sobre linguagem e diferença no intento de sinalizar algumas referências, para possíveis estudos e discussões da temática em relação à formação docente para a área de conhecimento de Ensino Religioso.

\section{Linguagem: um espaço de construção da diferença}

Um dos desafios na atualidade reside na compreensão de um dos fios que tecem as relações sociais: a linguagem. O ser humano vive em constante relação com outros seres humanos e, possivelmente, nesta relação, depara-se com uma infinidade de diferenças, que produzem os diferentes. Logo, o que está relacionado aos diferentes e à diferença tem como pano de fundo a linguagem e o que está relacionado e a linguagem tem como pano de fundo a diferença.

A linguagem, ao permitir a comunicação dos seres com o mundo, passa a ser a possibilidade concreta dos dados da realidade chegar à consciência. De acordo com Brandão (2004, p. 108), a linguagem precisa ser vista não "apenas como instrumento de comunicação de transmissão de informação ou como suporte do pensamento". Surgiu da necessidade dos seres humanos compartilharem suas idéias e pensamentos aos outros seres e, desse modo, entender e ser entendido. A linguagem é "interação, um modo de ação social" (BRANDÃO, 2004, p. 108), assim, não é possível pensar o ser humano no mundo isento das interações que realiza socialmente e isolado do discurso.

Somos constantemente interpelados por discursos que movimentam sentidos e posicionam os sujeitos socialmente, pois "quando se diz algo, alguém o diz de algum lugar da sociedade para outro alguém também de algum lugar da sociedade e isso faz parte da significação" (ORLANDI, 2003a, p. 26). Ao mesmo tempo em que a linguagem vai constituindo os sujeitos, esses se constituem no processo de desenvolvimento da linguagem.

A própria cultura se manifesta por diferentes formas de linguagens desenvolvidas ao longo da vivência humana, uma vez que a linguagem é a materialização da cultura, ela reflete o aspecto histórico-social da vida da

Rev. Diálogo Educ., Curitiba, v. 8, n. 23, p. 245-262, jan./abr. 2008 
humanidade; é a representação do que é vivido e desse modo "é lugar de conflito, de confronto ideológico em que a significação se apresenta em toda a sua complexidade. Investigar a linguagem é abarcá-la nessa complexidade, é apreender o seu funcionamento" (BRANDÃO, 2004, p. 108). Brandão (2004, p. 07) destaca que "qualquer estudo da linguagem é hoje, de alguma forma, tributário de Saussure, quer tomando-o como ponto de partida, assumindo suas postulações teóricas, quer rejeitando-as". Uma vez que a linguagem para Saussure se estrutura na diferença, nas dicotomias de presença e ausência do sistema lingüístico. Assim, o ser humano se relaciona com a realidade/mundo pela linguagem, organiza-a e de maneira semelhante organiza os sujeitos, cria sistemas de identificação, tanto de pertencimento como de exclusão.

Vygotsky (2000) compreendeu a linguagem como constituidora do sujeito uma vez que a comunicação só pode ocorrer de forma indireta, pois precisa passar primeiro pelos significados e depois pelas palavras. Assim, o sentido é gerado pela motivação, isto é, por desejos e necessidades, interesses e emoções. Segundo Vygotsky (2000, p. 182-188), para "compreender a fala de outrem não basta compreender suas palavras - temos que compreender seu pensamento", pois uma "palavra adquire o seu sentido no contexto em que surge: em contextos diferentes, altera o seu sentido". Desse modo, pode-se dizer que o sentido de uma palavra é a soma de todos os eventos psicológicos que a palavra desperta em nossa consciência.

Os sentidos que se pode dar ao mundo e à realidade são infinitos, pois "são construídos, produzidos no processo de interlocução" (BRANDÃO, 2004, p. 109). Os sentidos necessitam do social, por seus interlocutores para se realizar, uma vez que o social aparece em relação à linguagem, na sua força contraditória. Por o social ser "constitutivo da linguagem, esta se sedimenta (ilusão do sujeito), e porque ser fato social, ele muda (polissemia)" (ORLANDI, 2003a, p.28); assim, a apropriação da linguagem é social.

Como resultado da história social, a linguagem transformou-se em instrumento decisivo do conhecimento humano porque, por meio dela, o ser humano pôde superar os limites da experiência sensorial, individualizar as características dos fenômenos e formular determinadas generalizações ou categorias. Dessa forma, ela é decisiva para o desenvolvimento da atividade consciente dos sujeitos. De acordo com Luria (1986, p. 25), o elemento fundamental da linguagem é a palavra, pois ela "designa ações, relações, reúne objetos em determinados sistemas. Dito de outra forma, a palavra codifica nossa experiência".

Diante das muitas maneiras de significar a linguagem, constituise a Análise do Discurso, que trata então do discurso (ORLANDI, 2003b); isto é, como palavra em movimento - prática de linguagem. Os discursos são anteriores a nós, já existem no momento em que nascemos e a eles somos apresentados, uma vez que:

Rev. Diálogo Educ., Curitiba, v. 8, n. 23, p. 245-262, jan./abr. 2008 
Todo discurso nasce de outro discurso que reenvia a outro por isso não se pode falar em um discurso, mas em estado de um processo discursivo, e esse estado deve ser compreendido como resultando de processos discursivos sedimentados, institucionalizados. (ORLANDI, 2003a, p. 26).

Como vimos, ao nascer, somos inscritos nas formações discursivas que já existem na sociedade. Esta inscrição pode ser dada por meio da interação, que primeiramente ocorre no âmbito familiar e aos poucos esse círculo de interação vai se ampliando em outros discursos que têm seu espaço na dinâmica do cotidiano. Os meios de comunicação, as instituições (escola, igreja, etc.), entre outros discursos, sustentam os dizeres já-ditos, porque "o que é dito em outro lugar também significa nas nossas palavras" (ORLANDI, 2003b, p. 32). Dessa forma, o contexto discursivo vai se ampliando e constituindo o sujeito culturalmente, ao mesmo tempo em que a linguagem afeta as pessoas e é afetada por elas.

O discurso se constitui então, numa tensão básica entre o texto e o contexto histórico-social, pois todo texto apresenta um retorno constante a um mesmo dizer sedimentado - a paráfrase - e uma tensão que aponta para o rompimento, a polissemia. Há um conflito entre o que é garantido e o que tem de se garantir (ORLANDI, 2003a). O texto, segundo Orlandi (1992), é sempre um conjunto de formulações entre outras coisas possíveis, movimento do dizer face ao silêncio tomado aqui como horizonte discursivo, o a dizer e não o vazio. Logo, o processo de produção de sentidos está sujeito a deslizes, pois:

Há sempre um "outro" possível que constitui o mesmo [...]. Dito isto de outra maneira, o mesmo também é produto da historicidade, já é parte do efeito metafórico. A historicidade aí está justamente representada pelos deslizamentos (nas relações de paráfrase) que instalam o dizer no jogo das diferentes formações discursivas, presença de uma ausência necessária, relação incontornável com a alteridade. Falamos a mesma língua, mas falamos diferente. (ORLANDI, 2001, p. 24).

Na educação também é assim, pois todo educador é primeiramente um homem e uma mulher que, antes de ser educador, foi educado e continuamente se educa no cotidiano. Traz em seu corpo as marcas indeléveis da construção de sua própria história. História como ser social, religioso, familiar, político e acadêmico. De modo formal e informal, o ser humano vai incorporando e (res)significando conceitos e práticas que, no decorrer de sua vida, serão decodificados e ancorados a outros esquemas que, por sua vez, irão construindo o ser educador. Como afirma Paulo Freire (1993, p. 87):

Rev. Diálogo Educ., Curitiba, v. 8, n. 23, p. 245-262, jan./abr. 2008 
Não nasci, porém, marcado para ser um professor assim. Vim me tornando desta forma no corpo das tramas, na reflexão sobre a ação, na observação atenta a outras práticas ou a prática de muitos sujeitos.

Práticas pedagógicas e processos de formação de educadores, que omitirem ou minimizarem a historicidade dos sujeitos, suas pronúncias de mundo em vozes, discursos em linguagens diferenciadas correm o risco de abortar o desvelamento de possíveis espaços e lugares fecundos para a construção de outros sentidos e discursos. Para Catani (2000, p. 34) e colegas pesquisadoras:

As concepções sobre as práticas docentes não se formam a partir do momento em que os alunos e professores entram em contato com as teorias pedagógicas, mas encontram-se enraizadas em contextos e histórias individuais que antecedem, até mesmo, a entrada deles na escola, estendendo-se a partir daí por todo o percurso de vida escolar e profissional.

Neste constituir-se como outro, as identidades adquirem sentido por meio da linguagem e dos sistemas simbólicos pelos quais são representadas; assim, a construção da identidade e da diferença é tanto simbólica quanto social.

\section{A diferença e suas constituições}

Vivemos numa época de difusão das diferenças, pois somos contínua e intensamente interpelados por marcadores identitários, em que os sentimentos de pertencimento são cambiantes e complexos, difíceis de capturar, descrever e analisar. Apresentar uma discussão que contemple o conceito diferença é um exercício complexo, embora necessário. Complexo por considerar a diversidade de abordagens em torno desse conceito que implica adentrar em outros conceitos como identidade e alteridade. Diferença é entendida aqui não apenas como um conceito filosófico ou uma forma semântica, mas antes de tudo como uma realidade concreta, um processo humano, histórico e social, que a humanidade emprega em suas práticas cotidianas na vida em sociedade.

Segundo Burbules e Rice (1993), a noção de diferença evocada na literatura pós-moderna deriva principalmente de Jacques Derrida, embora sua origem esteja na lingüística saussuriana. Ainda de acordo com Burbules e Rice, para Saussure é a différence entre dois significantes que permite que eles sejam utilizados como tais. Nessa perspectiva, só podemos utilizar a letra ' $O$ ' e a letra ' $Q$ ' como tais porque há uma diferença entre elas, caso contrário seria a mesma coisa. Logo, é a diferença que nos constitui como tais e nos faz ser diferente, nos substancia em indivíduos.

Para Chediak (1999), ao se estabelecer à identidade se está determinando o lugar da diferença, ou seja, "as identidades são fabricadas por meio da marcação da diferença”" (WOODWARD, 2003, p. 39), assim, o termo

Rev. Diálogo Educ., Curitiba, v. 8, n. 23, p. 245-262, jan./abr. 2008 
identidade remete à questão da diferença, já que de acordo com Souza (1994, p. 17), "a identidade é o que, em princípio, nos diferencia dos outros".

A diferenciação entre identidade e diferença para Tomaz Tadeu da Silva (2003, p. 74) se apresenta como sendo "a identidade é simplesmente aquilo que se é: 'sou brasileiro' [...]" e "a diferença é aquilo que o outro é: 'ela é italiana' [...]". No contexto da religiosidade isto também é recorrente, pois ao afirmar que pertenço a uma tradição religiosa, estou confirmando que não pertenço a todas as outras. Ao falar de identidade, é preciso tomá-la no plural e vê-la incompleta, sempre em movimento, processo que não cessa jamais, construído pelo discurso e pela linguagem (SILVA, 2003).

A diferença precisa ser vista como uma característica da vida interior e não apenas como uma questão de embates entre diversos grupos. Segundo Silva (2003, p. 76); "seria preciso considerar a diferença não simplesmente como resultado de um processo, mas como o processo mesmo pelo qual tanto a identidade quanto a diferença (compreendida, aqui, como resultado) são produzidas". Para esse autor, abordar a identidade implica necessariamente uma abordagem da diferença uma vez que, "identidade e diferença são inseparáveis" (2003, p. 75).

Moreira (2002, p. 13) destaca que "[...] não basta reconhecer as diferenças, é preciso estabelecer relações entre as pessoas. Assim, trata-se de reconhecer o outro como pessoa e não a outra cultura como uma matéria a ser estudada". Em consonância com Moreira, Silva (2003) afirma que reconhecer este outro como pessoa implica reconhecer o outro como diferente. Mas, quem vem a ser este outro que é diferente?

Para Silva (2003, p. 97), "o outro é o outro gênero, o outro é a cor diferente, o outro é a outra sexualidade, o outro é o corpo diferente". Reconhecer o outro como diferente - implica ainda reconhecer alguém que difere do grupo ou na relação pessoa a pessoa. Para Oliveira (2003, p. 166), o diferente é aquele:

Que anda diferente, fala diferente, vê o mundo com outros olhos, tem cor da pele diferente, crê de modo diferente, deseja e se identifica de outro modo, pertence à outra cultura, a outra geração ou a outro grupo social. [...] presença, enquanto o ser e estar ali, em sua historicidade, provisoriedade, inconclusão, limitação, busca; enfim, em sua digna humanidade.

A diferença é marcada em relação à identidade pelos sistemas classificatórios como responsáveis pelo estabelecimento das formas de diferença nas relações sociais, embora o significado e o efeito de sentido façam parte da identidade pessoal de cada indivíduo, pois, "é um elemento central dos sistemas

Rev. Diálogo Educ., Curitiba, v. 8, n. 23, p. 245-262, jan./abr. 2008 
classificatórios por meio dos quais os significados são produzidos" (WOODWARD, 2003 , p. 67). Assim, a diferença pode ser entendida como "aquilo que separa uma identidade da outra, estabelecendo distinções" (WOODWARD, 2003, p. 41).

Para explicar a questão da diferença, Hall (2003a, p. 17) recorre a Laclau ao afirmar que:

As sociedades da modernidade tardia, [...], são caracterizadas pela "diferença"; elas são atravessadas por diferentes divisões e antagonismos sociais que produzem uma variedade de diferentes "posições de sujeito" - isto é, identidades - para indivíduos.

Segundo Louro (1997, p. 51), as múltiplas identidades "se interferem mutuamente, se articulam; podem ser contraditórias; provocam, enfim, diferentes "posições". Nesse sentido, os traços identitários parecem se singularizar nas diferenças, que, segundo Burbules (2003, p. 166), podem ser estabelecidas de fato no domínio social ao serem classificadas em categorias ${ }^{2}$ centrais onde incluiriam sexo, gênero, classe, etnia, cultura, língua, nacionalidade, religião, sexualidade, idade, capacidade ou incapacidade... a lista seria grande se fôssemos classificar em categorias.

A diferença, segundo Abbagnano (2000, p. 34), é "determinação da alteridade. A alteridade não implica em si nenhuma determinação [...] as coisas só podem diferir se têm em comum a coisa em que diferem. A diferença implica uma determinação [...]", essa reflexão postula um olhar para o outro, pois, para Abbagnano, "as coisas só podem diferir se têm em comum a coisa em que diferem". No que diz respeito à religiosidade, não é diferente, percebemos que só diferem se tem em comum a razão dessa diferença.

De acordo com Charaudeau e Maingueneau (2004), a alteridade deriva da noção da filosofia, que tinha como função construir uma relação fundada

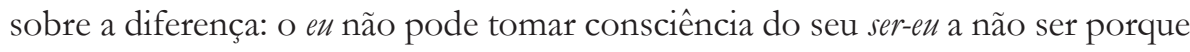
existe um não-en que é outro, que é diferente. Ela se opõe, então, ao conceito de identidade, que concebe a relação entre dois seres sob o modo do mesmo. Desta forma, a alteridade é a capacidade de conviver com o outro que é diferente e de se proporcionar um olhar para este outro a partir das diferenças. Significa que eu reconheço o outro também como sujeito de iguais direitos, embora os seres humanos tenham sido continuamente condicionados a manter-se extremamente fixados na valorização das suas diferenças individuais.

2 O termo categoria aqui é utilizado conforme Burbules, porém, para nálise do Discurso utilizam-se outros termos como sítios de ignificância, nichos de sentido para designar aproximações. A classificação em categorias revela as diferenças que são facilmente identificadas na sociedade, mas que não são objeto desta discussão.

Rev. Diálogo Educ., Curitiba, v. 8, n. 23, p. 245-262, jan./abr. 2008 
Para Villa (2000), na alteridade (heterotes), o não-ser deixa de ser o nada e passa a ser o outro do ser, o diferente dele (mónon héteron ekeínou), fazendo assim com que, de alguma maneira, o não-ser seja e com que todos os entes, enquanto realidades participem do outro, da alteridade, da diferença. Para compreender a alteridade parece pertinente entender a noção do outro, uma vez que esse é que constitui a alteridade.

O outro é concebido por Lévinas (1997) como significação, sentido por si só, onde tu és tu absolutamente e compreensão alguma pode abarcá-lo. O outro é o que não pode ser contido, que conduz para além de todo contexto e do ser. Compreender o ser, enquanto ser, é existir, é relacionar-se ao particular, único a existir, pelo conhecimento que é sempre conhecimento do universal. Segundo este autor, "compreender uma pessoa é já falar-lhe. Pôr a existência de outrem, deixando-a ser, é já ter aceitado essa existência, tê-la tomado em consideração" (LÉVINAS, 1997, p. 27).

Para Coracini (2003), em vez de falarmos de identidade como algo acabado, dever-se-ia vê-la como um processo em andamento e preferirmos o termo identificação, pois só é possível capturar momentos de identificação do sujeito com outros sujeitos, fatos e objetos. Toda identificação com algo ou alguém ocorre na medida em que essa voz encontra eco, no interior do sujeito, no inconsciente que o reconhece ou identifica sem necessariamente o consentimento do consciente.

Em uma linguagem mais coloquial, a identificação é construída a partir do reconhecimento de alguma característica em comum, enquanto a abordagem discursiva vê a identificação como uma construção, um processo nunca completado, algo sempre em processo. Para Hall (2003b), a identificação é vista como um processo de articulação, uma suturação, uma sobredeterminação, e não como uma subsunção que não anulará a diferença. Logo é possível perceber que na linguagem também se articula o exercício do poder, designam-se identidades e realizam-se identificações.

Nessa compreensão, o diferente é idealizado e efetivado nas relações humanas, onde as diferenças são evidenciadas e/ou silenciadas, por meio dos próprios seres humanos que marcados ideológica e sócio-historicamente produzem sentidos a partir de uma relação dialógica, num momento histórico-social único, responsável pelas condições de produção, que estabelecem comportamentos, atitudes e práticas sociais.

Formação de docentes para o Ensino Religioso e a LDBEN n. 9394/96: um espaço de encontro com as diferenças

Historicamente a formação de educadores em Ensino Religioso até a década de 90 era orientada, quase que na sua totalidade, pelas denominações religiosas cristãs e, em alguns casos, ela ocorria em parceria com os sistemas de ensino. Isso se dava em decorrência da linha confessional e/ou interconfessional.

Rev. Diálogo Educ., Curitiba, v. 8, n. 23, p. 245-262, jan./abr. 2008 
Para Figueiredo (1996), a reflexão iniciada na década de setenta com a promulgação e implantação da LDBEN 5.692/71, que apresentava o Ensino Religioso como oferta obrigatória por parte da Unidade Escolar, dando ao educando o direito de opção, gerou

um salto de qualidade na busca da identidade do ER, com distinção entre ER na escola e catequese na comunidade eclesial. Criaram-se programas de formação de professor e curriculares em que aspectos antropológicos, sociológicos, pedagógicos e políticos foram evidenciados, deixando para trás conteúdos doutrinários e práticas desvinculadas da experiência científica e cultural. (FIGUEIREDO, 1996, p. 05).

Uma das temáticas a envolver a reforma educativa brasileira, desencadeada a partir da década de oitenta, abordava a diversidade cultural presente nas escolas brasileiras e, em conseqüência, a necessidade de uma proposta de Ensino Religioso, que integrasse esse referencial. Um dos resultados dos estudos e reflexões foram a elaboração coletiva do documento Parâmetros Curriculares Nacionais de Ensino Religioso - PCNER - aprovado pelo Plenário do Fórum Nacional Permanente de Ensino Religioso - FONAPER ${ }^{3}$-, em março de 1996. Esse documento apresenta os referenciais para um Ensino Religioso que,

valorizando o pluralismo e a diversidade cultural presentes na sociedade brasileira, facilita a compreensão das formas que exprimem o Transcendente na superação da finitude humana e que determinam, subjacentemente, o processo histórico da humanidade; [...] por isso não deve ser entendido como Ensino de uma Religião ou das Religiões na Escola, mas sim uma disciplina centrada na antropologia religiosa. (FONAPER, 1997, p. 11-30).

A nova redação do artigo 33 da LDBEN n. 9394/96, promulgada pela Lei n. 9.475/97, alterou significativamente os encaminhamentos deste componente curricular, criando pela primeira vez na história brasileira "oportunidades de sistematizar o ensino religioso como disciplina escolar que

3 O FONAPER é "uma associação civil de direito privado, de âmbito nacional, sem vínculo político-partidário, confessional e sindical, sem fins lucrativos, com duração por tempo indeterminado, que congrega, conforme este Estatuto, pessoas jurídicas e pessoas naturais identificadas com o Ensino Religioso Escolar e se constitui em um organismo que trata questões pertinentes ao Ensino Religioso - ER, sem discriminação de qualquer natureza" FONAPER, Estatuto, cap. I, art. 1.

Rev. Diálogo Educ., Curitiba, v. 8, n. 23, p. 245-262, jan./abr. 2008 
não seja doutrinação religiosa e nem se confunda com o ensino de uma ou mais religiões" (ZIMERMANN, 1997, p. 10). O texto de lei trouxe uma nova configuração e conseqüentemente um outro espaço ao Ensino Religioso em âmbito nacional. Em caráter de matrícula facultativa, é compreendido como parte integrante da formação básica do cidadão, constitui disciplina dos horários normais das escolas públicas do ensino fundamental e deve assegurar o respeito à diversidade cultural religiosa do Brasil - vedadas quaisquer formas de proselitismo (BRASIL, 1997).

Segundo Junqueira (2002), a mudança de paradigma na concepção do Ensino Religioso, a elaboração dos PCNER e a busca de definição de Diretrizes Curriculares Nacionais para a formação de docentes para esta área do conhecimento ${ }^{4}$ junto ao Ministério da Educação e Cultura - MEC passaram a exigir novas propostas de formação para os educadores.

$\mathrm{Na}$ atualidade, a criação e oferta de cursos de graduação, especialização e extensão em diferentes locais do território brasileiro; a realização de fóruns, seminários, debates e similares envolvendo denominações religiosas, comunidade acadêmica e sistemas de ensino são alguns dos lugares, que mobilizam, subsidiam e conduzem as reflexões sobre a formação de educadores para o Ensino Religioso.

Neste contexto, diferentes vozes se pronunciam, elaboram e revelam mapas cujos sentidos e significados circunscrevem espaços e lugares históricos, que se percebem desafiados por novos tempos, concepções e práticas docentes (OLIVEIRA et al., 2007). Transitar e interagir com a diversidade de territórios e territorialidades, que ali se fazem presentes é altamente desafiador. Religiosidade, fé e religião são traços que podem constituir identitariamente cada ser humano e conseqüentemente estão presentes em todas as culturas humanas. No entanto, cada grupo dispõe de marcadores individuais, que os tornam singulares num contexto plural.

De acordo com os PCNER, espera-se do profissional de Ensino Religioso que este tenha sensibilidade à pluralidade, consciência da complexidade sociocultural da questão religiosa presente no ambiente escolar e garanta a liberdade dos educandos sem qualquer forma de proselitismo; esteja disponível para o diálogo e seja capaz de articulá-lo a partir de questões suscitadas no processo de aprendizagem destes. Cabe a esse educador escutar, facilitar o diálogo, ser o interlocutor entre Escola e Comunidade e mediar os possíveis conflitos no contexto educativo (FONAPER, 1997).

4 A Resolução da CEB do CNE 02/98 apresenta o Ensino Religioso como uma das dez áreas de conhecimento do Ensino Fundamental.

Rev. Diálogo Educ., Curitiba, v. 8, n. 23, p. 245-262, jan./abr. 2008 
Os requisitos para um profissional de Ensino Religioso sinalizam no como não fazer proselitismo. O educador se constitui cultural e historicamente, portanto se relacionando ou não, de forma indireta ou direta com uma ou mais expressões religiosas e ao se pronunciar sua voz fala desse lugar, ou lugares. Conforme Orlandi (1998, p. 13), "os sentidos e o sujeito se constituem ao mesmo tempo no interior de uma formação discursiva no confronto entre as diferentes formações" e "as formações discursivas não têm fronteiras categóricas" (ORLANDI, 1998, p. 11). Neste entendimento, como pode o educador neutralizar os seus discursos, como pode abrir mão de sua ideologia, se isto é o que o constitui? Parece não ser possível compreender o proselitismo como palavra neutra, pois, mesmo quando o indivíduo procura a neutralidade, há o deslize, os silêncios significativos, as palavras do não discurso impregnadas de ideologia.

Por essas razões, o cotidiano escolar e a formação de educadores requerem práticas em espírito de ética e alteridade das realidades dos sujeitos e conteúdos elaborados historicamente pelos diferentes povos em relação ao sagrado (FONAPER, 1997). Para tanto são imprescindíveis processos de formação docente, que discutam e pesquisem em profundidade estas questões, tendo na linguagem um espaço cujos lugares habitados por significados e sentidos pessoais e coletivos, que ao serem acolhidos, ouvidos e decodificados podem contribuir expressivamente para o encontro dos sujeitos e realidades diferenciados, trazendo possibilidades para um exercício formador atento e pautado na diversidade.

O contexto das culturas e das religiões é atravessado pelas diversidades, que as constituem historicamente. A linguagem busca expressar, anunciar e pronunciar os diferentes sentimentos e posturas que pessoas, culturas e povos vão organizando e expressando em relação ao que os circundam. Nesse sentido, expressões usadas no cotidiano e aparentemente tão simples quanto: religião, religiosidade, sagrado, fé e muitas outras trazem diferente sentidos em diferentes contextos sociais, políticos ou culturais. Muitas vezes esses sentidos tornam-se contraditórios entre si, podendo, assim, provocar conflitos de idéias e guerras entre nações, uma vez que, como afirma Silva (2003, p. 97), "mesmo quando explicitamente ignorado e reprimido, a volta do outro, do diferente, é inevitável, explodindo em conflitos, confrontos, hostilidades e até mesmo violência".

Parece residir nos sentidos e nas particularidades de sentidos a necessidade de uma busca de compreensão e percepção diferenciada das diferenças e conseqüentemente dos diferentes. Segundo Teixeira (1993, p. 07), mediante a diversidade cultural religiosa, o diálogo inter-religioso apresenta-se hoje como um dos grandes desafios a ser trabalhado pelas diversas tradições religiosas. Para Geffré (1993, p. 68), “[...] viver a fé na era do diálogo inter-religioso ensina-nos a pensar o absoluto que reivindicamos como um absoluto relacional e não como

Rev. Diálogo Educ., Curitiba, v. 8, n. 23, p. 245-262, jan./abr. 2008 
um absoluto de exclusão ou de inclusão". Desse modo, podemos afirmar que onde as diferenças são eliminadas, o diálogo se torna impossível.

Entretanto, quando se respeitam às diferenças, o diálogo pode tornarse possível. Mas, para que isso aconteça, segundo Sobel (1996, p. 01), "é preciso cultivar o respeito mútuo entre os seres humanos. [...] o que se faz necessário não é a tolerância, e sim um respeito de reverência, reverência pela diversidade, diversidade pelas crenças alheias". O diálogo, para Freire (2001, p. 78-79), é o encontro dos seres humanos, "mediatizados pelo mundo, para pronunciá-lo, não se esgotando, portanto, na relação eu-tu", assim, "é uma exigência existencial". Uma vez que para esse autor, "existir humanamente, é pronunciar o mundo, é modificá-lo” (FREIRE, 2001, p. 78).

Estas são algumas das questões, que obrigatoriamente devem perpassar uma reflexão mais acurada sobre os pressupostos curriculares de um processo de formação docente para o Ensino Religioso inspirado nos princípios de liberdade e solidariedade humana, que inserido num projeto de educação superior de acordo com a LDBEN 9394/96 (art. 43, VI); tem como uma de suas finalidades "estimular o conhecimento dos problemas do mundo presente, em particular os nacionais e regionais, prestar serviços especializados à comunidade e estabelecer com esta uma relação de reciprocidade".

\section{A guisa de considerações finais}

Diante de uma realidade caracterizada pela diversidade religiosa presente na sociedade e cotidiano escolar, não há mais condições de uma perspectiva de entrincheiramento, de fixação num único itinerário, sem se dar conta da singularidade e riqueza de outros caminhos. A abertura ao outro, a permeabilidade para a dinâmica da relação, do reconhecimento do diferente como enriquecimento do singular, aparecem na atualidade como passagens imprescindíveis para a construção da identidade.

O diálogo, na concepção de Freire, é um espaço de interação e educação que provoca e encaminha a libertação comunitária. Nesse exercício saberes são socializados revendo situações, limites, posturas, decisões, em um movimento, que atinge, emociona, desaloja e desafia o individual e o coletivo, onde o objetivo e o subjetivo se casam numa dança em que o corpo expressa o conflito e o desejo do surgimento de uma nova consciência, um novo passo. Nesse lugar de encontros, para ele, "não há ignorantes absolutos, nem sábios absolutos: há homens que em comunhão buscam saber mais" (FREIRE, 2001, p. 81) homens e mulheres que na (re)apropriação de suas palavras e sentidos vão sendo mais, conhecendo-se e reconhecendo-se sujeitos e agentes da e na história.

Rev. Diálogo Educ., Curitiba, v. 8, n. 23, p. 245-262, jan./abr. 2008 
Um processo de formação docente com vistas à construção de educadores comprometidos com a vida solidária em uma perspectiva de planetaridade deverá passar impreterivelmente pelo exercício do diálogo, que busca identificar nos sentidos e significados dos sujeitos espaços e lugares para encontros nas diferenças. Para Freire (2000), uma formação docente conduzida em diálogo e ética que encoraje posturas, onde o gosto da pergunta, o respeito e acolhida à diferença, o deleite no ouvir e a paixão de saber em curiosidade e alegria no criar, prazer de conviver constitui a liturgia de um processo libertador e inovador nas vidas dos que ali se descobrem e se encontram.

O diálogo se efetiva na convivência entre homens e mulheres, desafiando e transformando a práxis em gestão. Enseja a democracia e gratuidade nas relações com vistas à superação das situações dicotômicas de uma sociedade injusta e opressora. De acordo com os PCNER, o educador de Ensino Religioso tem, no diálogo, a ferramenta mater para o acesso, a decodificação e ressignificação de situações, questionamentos e posturas que compõem o espaço educativo. A palavra, mediadora no sentido dialógico da conversação, apresenta-se qual lança problematizadora no processo educativo. Essa palavra vem carregada com seus significados e sentidos emergenciais, abarcando todo um universo particular e socialmente vivido, construído paulatinamente no cotidiano (FONAPER, 1997).

Enquanto sujeito histórico, em permanente processo de construção com outros sujeitos históricos, o educador ver-se-á coagido a usar de coerência e responsabilidade como decorrência de sua competência. As palavras mundo pronunciadas e escritas reclamam ações condizentes e alimentadoras no processo de conscientização, que trafega pelo aprender a aprender, aprender a fazer, aprender a ser e transcendem o espaço docente. Neste contexto, perguntamo-nos: Se a linguagem é portadora de sentidos que podem originar conflitos e mazelas culturais, não poderia ser ela também a mensageira e viabilizadora de outras pronúncias de mundo, uma vez que no conjunto gerador de suas palavras reside também o poder de criação e recriação?!

\section{REFERÊNCIAS}

ABBAGNANO, Nicola. Dicionário de filosofia. Tradução coordenada por Alfredo Bosi; revisão da tradução e tradução dos novos textos Ivone Castilho Benedetti. 4. ed. São Paulo: Martins Fontes, 2000.

BRANDÃO, Helena, H. Nagamine. Introdução à análise do discurso. 2. ed. rev. Campinas, SP: Editora da UNICAMP, 2004.

BRASIL. Ministério da Educação. Lei de Diretrizes e Bases da Educação Nacional n. 9394/96. Brasilia. Disponível em: <http:/ /www.planalto.gov.br/ CCIVIL_03/LEIS/L9394.htm>. Acesso em: 15 fev. 2008.

Rev. Diálogo Educ., Curitiba, v. 8, n. 23, p. 245-262, jan./abr. 2008 
. Ministério da Educação. Lei n. 9.475/97. Brasília. Disponível em: http://www.planalto.gov.br/CCIVIL_03/LEIS/L9475.htm. Acesso em: 15 fev. 2008.

BURBULES Nicholas C.; RICE. Diálogo entre as diferenças: continuando a conversação. In: SILVA, Tomaz Tadeu da (Org.). Teoria educacional crítica em tempos pós-modernos. Porto Alegre: Artes Médicas, 1993. p. 173-203.

BURBULES, Nicholas C. Uma gramática da diferença: algumas formas de repensar a diferença e a diversidade como tópicos educacionais. In: GARCIA, Regina Leite; MOREIRA, Antonio Flavio Barbosa (Org). Currículo na contemporaneidade: incertezas e desafios. Tradução de Silvana Cobucci Leite, Beth Honorato, Dinah de Abreu Azevedo. São Paulo: Cortez, 2003. p. 159 -188.

CATANI, Denice Bárbara; SOUSA, Cynthia Pereira de; SOUZA, M. Cecília C. História, memória e autobiografia na pesquisa educacional e na formação. In: CATANI, Denice Bárbara (Org.). Docência, memória e gênero: estudos sobre formação. São Paulo: Escritura, 2000. p. 13-46.

CHARAUDEAU Patrick; MAINGUENEAU Dominique. Dicionário de análise do discurso. Coordenação da tradução Fabiana Komesu. São Paulo: Contexto, 2004.

CHEDIAK, Karla de Almeida. Introdução à filosofia de Deleuze: um estudo crítico sobre o conceito de diferença na filosofia da representação finita e infinita. Londrina: UEL, 1999.

CORACINI, Maria José R. Faria (Org.). Identidade e discurso: (des)construindo subjetividades. Campinas, SP: Editora da UNICAMP; Chapecó: Argos Editora Universitária, 2003.

FIGUEIREDO, Anísia de Paulo. Ensino religioso no Brasil hoje. Jornal Contexto Pastoral, Rio de Janeiro, 1996, p. 05.

FREIRE, Paulo. Política e educação. São Paulo: Cortez, 1993. 119 p. (Coleção questões da nossa época; v. 23).

Pedagogia da autonomia: saberes necessários à prática educativa. 15. ed. Rio de Janeiro: Paz e Terra, 2000. 165 p.

Terra, 2001.

Pedagogia do oprimido. 30 ed. Rio de Janeiro: Paz e

Rev. Diálogo Educ., Curitiba, v. 8, n. 23, p. 245-262, jan./abr. 2008 
FONAPER, Fórum Nacional Permanente do Ensino Religioso. Parâmetros curriculares nacionais do ensino religioso. 2. ed. São Paulo: Ave Maria, 1997.

GEFFRÉ, Claude. A fé na era do pluralismo religioso. In: TEIXEIRA, Faustino Couto (Org.). Diálogo de pássaros: nos caminhos do diálogo inter-religioso. São Paulo: Paulinas, 1993.

HALL, Stuart. A identidade cultural na pós-modernidade. 8. ed. Tradução de Tomaz Tadeu da Silva, Guacira Lopes Louro. Rio de Janeiro, DP\&A, 2003a.

Quem precisa de identidade? In: SILVA, Tomaz Tadeu da (Org.). Identidade e diferença: a perspectiva dos estudos culturais. 2. ed. Petrópolis: Vozes, 2003b. p. 103-133.

JUNQUEIRA, Sérgio Rogério Azevedo. O processo de escolarização do ensino religioso no Brasil. Petrópolis: Vozes, 2002.

LÉVINAS, Emmanuel. Entre nós: ensaios sobre a alteridade. Coordenador da tradução Pergentino Stefano Pivatto. Petrópolis: Vozes, 1997.

LOURO, Guacira Lopes. Gênero, sexualidade e educação: uma perspectiva pós-estruturalista. Petrópolis: Vozes, 1997.

LURIA, Alexandre Romanovich. Pensamento e linguagem: as últimas conferências de Luria. Tradução Diana Myriam Lichtenstein e Mário Corso. Supervisão de tradução de Sérgio Spritzer. Porto Alegre: Artes Médicas, 1986.

MOREIRA, A. F. B. Currículo, diferença cultural e diálogo. In: Revista educação \& sociedade, Campinas, v. 23, n. 79, p. 5-20, ago. 2002.

OLIVEIRA, Lilian Blanck. Formação de docentes para o ensino religioso: perspectivas e impulsos a partir da ética social de Martinho Lutero. 2003. 239 f. Tese (Doutorado em Teologia área de concentração: Educação e Religião) - Escola Superior de Teologia, Instituto Ecumênico de Pós-Graduação em teologia, São Leopoldo, 2003.

. et al. Ensino religioso: fundamentos e métodos. São Paulo: Cortez, 2007. (Coleção docência em formação. Série ensino fundamental).

; SCHLÖGEL, Emerli. Abrindo janelas: um desafio à formação de educadores além territórios e territorialidades. Revista Religião e Cultura, São Paulo, v. 6, n. 11, p. 99-105, jan./jun. 2007.

Rev. Diálogo Educ., Curitiba, v. 8, n. 23, p. 245-262, jan./abr. 2008 
ORLANDI, Eni Puccinelli. As formas do silêncio: no movimento dos sentidos. Campinas: UNICAMP, 1992. . (Org.). A leitura e os leitores. Campinas: Pontes, 1998.

Discurso e texto: formulação e circulação dos sentidos. Campinas: Pontes, 2001.

A linguagem e seu funcionamento: as formas do discurso. 4. ed. Campinas: Pontes, 2003 a.

Análise do discurso: princípios \& procedimentos. 5. ed. Campinas: Pontes, 2003b.

SILVA, Tomaz Tadeu da. Identidade e diferença: a perspectiva dos estudos culturais. 2. ed. Petrópolis: Vozes, 2003.

SOBEL, Henry I. Construindo a paz na sociedade contemporânea, São Paulo: [s.n.], 1996. Apostila.

SOUZA, Octavio. Fantasias de Brasil. São Paulo: Escuta, 1994.

TEIXEIRA, Faustino Couto (Org.). Diálogo de pássaros: nos caminhos do diálogo inter-religioso. São Paulo: Paulinas, 1993.

VILLA, Mariano Moreno. Dicionário de pensamento contemporâneo. Tradução coordenada por Honório Dalbosco. São Paulo: Paulus, 2000.

VIGOTSKI, L. S. Pensamento e linguagem. Tradução de Jefferson L. Camargo. São Paulo: Martins Fontes, 2000.

WOODWARD, Katryn. Identidade e diferença: uma introdução teórica e conceitual. In: SILVA Tomaz Tadeu da (Org.). Identidade e diferença: a perspectiva dos estudos culturais. 2. ed. Petrópolis: Vozes, 2003. p. 7-72.

ZIMERMANN, Roque. Ensino religioso: uma grande mudança. Brasília: Câmara dos deputados, 1997.

Recebido: 23/09/2007

Received: 09/23/2007

Aprovado: 05/11/2007

Approved: 11/05/2007

Rev. Diálogo Educ., Curitiba, v. 8, n. 23, p. 245-262, jan./abr. 2008 